\title{
Influence of abutment model materials on the fracture loads of three-unit fixed dental prostheses
}

\author{
Timea WIMMER ${ }^{1}$, Kurt-Jürgen ERDELT ${ }^{1}$, Marlis EICHBERGER ${ }^{1}$, Malgorzata ROOS ${ }^{2}$, Daniel EDELHOFF ${ }^{1}$ \\ and Bogna STAWARCZYK ${ }^{1}$
}

\author{
${ }^{1}$ Department of Prosthodontics, Dental School, Ludwig-Maximilians-University, Munich, Germany \\ ${ }^{2}$ Division of Biostatistics, Institute of Social and Preventive Medicine, University of Zurich, Switzerland \\ Corresponding author, Timea WIMMER; E-mail: timea.wimmer@med.uni-muenchen.de
}

\begin{abstract}
This study evaluated and compared the influence of different supporting abutment models on the fracture loads of three-unit fixed dental prostheses (FDPs) fabricated from the following materials ( $n=24 /$ material): (i) IPS e.max CAD-on, (ii) IPS e.max ZirCAD, and (iii) Telio CAD. Twelve FDPs of each group were adhesively cemented on a polymeric model and on a base metal alloy one. For the fracture load test the FDPs were loaded at the centre of the pontic $(1 \mathrm{~mm} / \mathrm{min})$. The data were analyzed using descriptive statistics, two- and one-way ANOVA followed by post-hoc Scheffé test and Weibull statistics. Fracture loads were found to be affected by the choice of materials used for the abutment models. The fracture load for zirconia FDPs cemented on metal abutments was higher than on polymeric abutment group. In contrast, Telio CAD cemented on polymeric abutments presented higher fracture loads than group on base metal alloy support.
\end{abstract}

Keywords: Fracture load, Polymeric abutment model, Base metal alloy abutment model, Zirconia, Polymeric CAD/CAM materials

\section{INTRODUCTION}

In-vitro studies are often used to evaluate the clinical potential of dental restorations in order to prevent restoration failure. The results may indicate if further clinical investigations are reasonable and if a therapeutic benefit for patients can be expected. However, there is a great variety of testing conditions. Extracted natural teeth can be used to simulate the abutments as closely as possible to the oral conditions with regard to the elastic modulus, the bonding characteristics and mechanical stability ${ }^{1-5)}$. However, human teeth are rare and a sufficient number of specimens is essential to achieve appropriate statistical power. Furthermore, the significance of investigations on extracted human teeth is limited because of the natural variations in condition and shape. For this reason, many in-vitro studies use artificial teeth. Attributable to their standardized material properties the significance of in-vitro studies may be improved. Most studies use base metal alloy abutments as substitutes for natural teeth ${ }^{2,5-9)}$. The advantages of alloy are that the residual deformation during loading is limited compared to less stiff materials and that the abutments can be reused, thus reducing $\operatorname{costs}^{8}$. Cost reduction is also the reason resin abutments are often favored. They are inexpensive and have mechanical properties similar to those of natural teeth, thereby providing support close to that provided by nature ${ }^{10-13)}$. Test set-ups also vary with regard to the composition of the model. The holder and the abutments can be made on the whole from one material ${ }^{7,11,14)}$ or the model and the abutments can be fabricated separately with the option of additionally simulating the periodontal ligament ${ }^{2,3,8,10,12)}$. Diverse test setups, however, limit the comparability of the studies.
Moreover, the different mechanical properties of the substitute materials may limit test significance. The elastic modulus of the abutment has been found to have a crucial impact on the fracture load of dental restorations ${ }^{2,14-16)}$. Many studies observed the impact of abutment material on fracture load results of allceramic and alloy crowns ${ }^{2)}$. Concerning investigations on fixed dental prostheses (FDPs) on different abutment materials, however, only one study was found in literature ${ }^{15}$. The authors compared the fracture load of all-ceramic three-unit FDPs cemented on human teeth, polymeric or alloy abutments. A clear overestimation of the ceramic FDPs was found when the alloy abutments were applied. To our best knowledge, there are no studies which evaluate the influence of the abutment material on the fracture load of polymeric CAD/CAM FDPs. Therefore, the purpose of this study was to examine and compare the influence of the supporting abutment model on the fracture load of three-unit FDPs. Three different CAD/CAM materials were evaluated: a temporary polymeric material as monolithic FDPs, monolithic zirconia and veneered zirconia. The hypothesis tested was that fracture load increases with a higher elastic modulus of the abutment model, regardless of the FDPs material.

\section{MATERIALS AND METHODS}

This study tested the fracture load of three-unit FDPs from three different CAD/CAM materials cemented on two different abutment models. Table 1 gives detailed information of the materials used in this study.

\section{Specimen preparation}

A standardized anatomically supported model with 
Table 1 Summary of products used

\begin{tabular}{|c|c|c|c|c|}
\hline Materials & Components & Manufacturers & $\begin{array}{c}\text { Elastic } \\
\text { modulus } \\
{[\mathrm{GPa}]}\end{array}$ & Lot. No. \\
\hline \multicolumn{5}{|l|}{ FDPs } \\
\hline $\begin{array}{l}\text { Telio CAD } \\
\text { (temporary polymeric material) }\end{array}$ & PMMA & $\begin{array}{l}\text { Ivoclar Vivadent, } \\
\text { Schaan, Liechtenstein }\end{array}$ & 3.2 & $\mathrm{R} 28431$ \\
\hline $\begin{array}{l}\text { IPS e.max ZirCAD } \\
\text { (monolithic zirconia) }\end{array}$ & $\begin{array}{l}\mathrm{ZrO}_{2}, \mathrm{HfO}_{2}, \mathrm{Al}_{2} \mathrm{O}_{3}, \mathrm{Y}_{2} \mathrm{O}_{3} \\
\quad \text { and other oxides }\end{array}$ & $\begin{array}{l}\text { Ivoclar Vivadent, } \\
\text { Schaan, Liechtenstein }\end{array}$ & 220 & $\begin{array}{l}\text { R51403, } \\
\text { R53604 }\end{array}$ \\
\hline $\begin{array}{l}\text { IPS e.max CAD-on } \\
\text { (veneered zirconia) }\end{array}$ & - & $\begin{array}{l}\text { Ivoclar Vivadent, } \\
\text { Schaan, Liechtenstein }\end{array}$ & - & - \\
\hline $\begin{array}{l}\text { IPS e.max ZirCAD } \\
\text { (zirconia framework) }\end{array}$ & $\begin{array}{l}\mathrm{ZrO}_{2}, \mathrm{HfO}_{2}, \mathrm{Al}_{2} \mathrm{O}_{3}, \mathrm{Y}_{2} \mathrm{O}_{3} \\
\quad \text { and other oxides }\end{array}$ & $\begin{array}{l}\text { Ivoclar Vivadent, } \\
\text { Schaan, Liechtenstein }\end{array}$ & 220 & $\begin{array}{l}\text { R51403, } \\
\text { R53604 }\end{array}$ \\
\hline $\begin{array}{l}\text { IPS e.max CAD } \\
\text { (veneer) }\end{array}$ & $\begin{array}{l}\mathrm{SiO}_{2}, \mathrm{Li}_{2} \mathrm{O}, \mathrm{K}_{2} \mathrm{O}, \mathrm{MgO}, \mathrm{Al}_{2} \mathrm{O}_{3}, \mathrm{P}_{2} \mathrm{O}_{5} \\
\quad \text { and other oxides }\end{array}$ & $\begin{array}{l}\text { Ivoclar Vivadent, } \\
\text { Schaan, Liechtenstein }\end{array}$ & 95 & R49412 \\
\hline $\begin{array}{l}\text { CAD Crystall./Connect } 3 \\
\text { (fusion) }\end{array}$ & $\begin{array}{l}\text { Oxides, water, butanediol } \\
\text { and chloride }\end{array}$ & $\begin{array}{l}\text { Ivoclar Vivadent, } \\
\text { Schaan, Liechtenstein }\end{array}$ & - & $\mathrm{R} 22571$ \\
\hline $\begin{array}{l}\text { IPS e.max CAD Crystall./Glaze } \\
\text { (glaze) }\end{array}$ & Butanediol & $\begin{array}{l}\text { Ivoclar Vivadent, } \\
\text { Schaan, Liechtenstein }\end{array}$ & - & $\mathrm{R} 28730$ \\
\hline
\end{tabular}

Cement

Bis-GMA, UDMA, TEGDMA, inorganic fillers (barium glass, ytterbium trifluoride,

Variolink II

Ba-Al-fluorosilicate glass, spheroid mixed oxide), catalysts, stabilizers, pigments

$\begin{array}{cc}\text { Ivoclar Vivadent, } & \text { R46653, } \\ \text { Schaan, Liechtenstein } & \text { R42290 }\end{array}$

Models

\begin{tabular}{|c|c|c|c|}
\hline Acrylglas GS (polymer) & PMMA & $\begin{array}{l}\text { Quinn Plastics, } \\
\text { Mainz, Germany }\end{array}$ & 3.3 \\
\hline STM extra (base metal alloy) & $\mathrm{Cr}, \mathrm{Ni}, \mathrm{Mn}, \mathrm{Si}, \mathrm{S}, \mathrm{C}$ & $\begin{array}{c}\text { STM Stahl, } \\
\text { Gräfelfing, Germany }\end{array}$ & 200 \\
\hline
\end{tabular}

Abbreviations in alphabetical order: $\mathrm{Al}_{2} \mathrm{O}_{3}$, Aluminium oxide; Bis-GMA, Bisphenol A diglycidylmethacrylate; Ba-Alflourosilicate glass, Barium aluminium fluorosilicate glass; C, Carbon; Cr, Chromium; $\mathrm{HfO}_{2}$, Hafnium oxide; $\mathrm{K}_{2} \mathrm{O}$, Potassium oxide; $\mathrm{Li}_{2} \mathrm{O}$, Lithium oxide; MgO, Magnesium oxide; Mn, Manganese; Ni, Nickel; $\mathrm{P}_{2} \mathrm{O}_{5}$, Phosphorus pentoxide; PMMA, Polymethyl methacrylate; S, Sulfur; Si, Silicon; $\mathrm{SiO}_{2}$, Silicon dioxide; TEGDMA, Triethyleneglycol dimethacrylate; UDMA, Urethane dimethacrylate; $\mathrm{Y}_{2} \mathrm{O}_{3}$, Yttrium oxide; $\mathrm{ZrO}_{2}$, Zirconia.

two abutments simulating an FDP between a second premolar and a second molar was designed with a CAD-program (SolidWorks, Concord, Massachusetts USA) (Fig. 1). The geometry for the tooth model was based on a dental anatomy textbook and on the measurements of a tooth mobility simulation device presented in a previous study ${ }^{17-18)}$. The abutment teeth were modelled according to a standard three-unit FDP design utilizing complete crown preparations with a $0.85 \mathrm{~mm}$ deep chamfer margin design, an occlusal reduction of $1.7 \mathrm{~mm}$ and a total convergence angle of $5^{\circ}$. The abutment models were milled (Gembacher, Bergen, Germany) from the two different materials a) polymeric block (PMMA-based, Acrylglas GS Quinn Plastics, Mainz, Germany) and b) base metal alloy block ( $\mathrm{Ni}$ - $\mathrm{Cr}$ alloy, STM extra, STM Stahl, Gräfelfing, Germany). Subsequently, anatomically supported three-unit FDPs were constructed with a CAD-program (CEREC inLab, Sirona, Bensheim, Germany) with a span of $7 \mathrm{~mm}$ between both abutment teeth. Connectors had cross-sectional areas of $31.3 \mathrm{~mm}^{2}$ distal and mesial, an occlusogingival height of $7 \mathrm{~mm}$, and a buccolingual width of $5.7 \mathrm{~mm}$ (Fig. 1). In the middle of the pontic a cavity was formed congruent to the loading stainless steel ball (diameter $4 \mathrm{~mm}$ ), ensuring a three-point-contact between the steel ball and the occlusal surface. In the first step, the CAD-on FDPs comprising the zirconia framework (IPS e.max ZirCAD, Ivoclar Vivadent) with an anatomically shaped occlusal area and the veneer (IPS e.max CAD, Ivoclar Vivadent) were constructed 


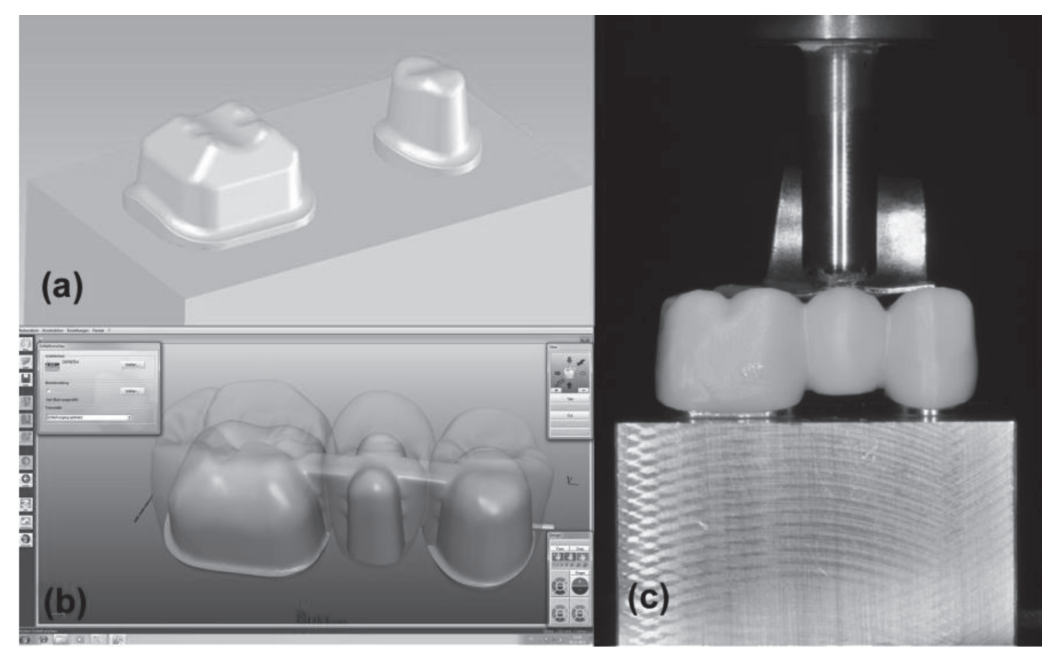

Fig. 1 Fracture load measurement: (a) design of the standardized anatomically supported model, (b) construction of both framework and veneering using CAD-software before milling, (c) finished FDP cemented on the alloy model for fracture load test.

and milled (inLab MC XL, Sirona) in a white state (partially sintered) and a blue state (pre-crystallized), respectively. The zirconia frameworks were sintered (Programat S1, Ivoclar Vivadent). Subsequently, the sintered zirconia frameworks and the pre-crystallized veneers were fused together (IPS e.max CAD Crystall./ Connect 3, Ivoclar Vivadent), crystallized and glazed (IPS e.max CAD Crystall./Glaze, Ivoclar Vivadent) in a ceramic furnace (Progamat EP 5000, Ivoclar Vivadent) according to the manufacturer's instructions. For standardized manufacturing of the Telio CAD and the monolithic zirconia FDPs with identical geometry, one CAD-on FDP was scanned. Telio CAD and IPS e.max ZirCAD were milled (inLab MC XL, Sirona) and zirconia FDPs were sintered (Programat S1, Ivoclar Vivadent). In summary, twenty-four FDPs of each tested material were fabricated. To avoid any operator influence one qualified technician produced all specimens.

Subsequently, $24 \mathrm{~h}$ before the fracture load measurements, twelve FDPs of each group were adhesively cemented on the polymeric model and the remaining twelve FDPs on the base metal alloy abutments using resin cement (Variolink II, Ivoclar Vivadent) according to the manufacturer's instruction.

Before cementation, the inner surfaces of all FDPs were air-abraded using alumina powder (10 s, 0,5 bar, distance: $10 \mathrm{~mm}$ ) with a mean particle size of $50 \mu \mathrm{m}$ (Fineblaster type FG 3, Sandmaster, Zofingen, Switzerland) and ultrasonically cleaned in distilled water (Sonorex, Bandelon electronic, Berlin, Germany) for $10 \mathrm{~min}$. The metal and the polymeric abutments were not pre-treated. For cementation, a special cementing device was used to ensure that the pontic was loaded centrally at a force of $750 \mathrm{~g}$ for $10 \mathrm{~min}$.

\section{Fracture load test}

The fracture load test was performed in a universal testing machine (Zwick/Roell 1445, Zwick, Ulm, Germany). The specimens were loaded at the centre of the pontic from the occlusal-gingival direction with a ball (diameter 4 $\mathrm{mm}$ ) until fracture of either the veneer or of the FDP itself occurred (crosshead speed $1 \mathrm{~mm} / \mathrm{min}$ ). In order to avoid force peak, a piece of $0.5 \mathrm{~mm}$ tin foil (Dentaurum, Ispringen, Germany) was positioned between the pontic and the loading ball (Fig. 1).

\section{Statistical methods}

For the development of the study design, the power analysis was calculated using the nQuery Advisior (Version 6.04.10, Statistical Solutions, Saugaus Mass). One pilot study with 8 specimens was performed with a zirconia CAD-on group cemented on polymeric abutments. The group showed two different fracture types, namely chipping and total fracture. Chipping was observed at $832.5 \pm 142 \mathrm{~N}$ and the total fracture at $2571.6 \pm 272 \mathrm{~N}$. A sample size of twelve in each group will have $92 \%$ power to detect a difference of $208 \mathrm{~N}$ in means $(25 \%$ observed fracture load chipping on resin abutments) between both abutment material types (base metal alloy or resin abutments) assuming that the common standard deviation is $142 \mathrm{~N}$ using a two group $t$-test with 0.05 two-sided significance level. In contrast, a sample size of twelve in each group will have $99 \%$ power to detect a difference of $643 \mathrm{~N}$ in means (25\% observed total fracture load on resin abutments) between both abutment material types (base metal alloy or resin abutments) assuming that the common standard deviation is $272 \mathrm{~N}$ using a two group t-test with 0.05 two-sided significance level.

The adjusted Anderson-Darling goodness-of-fit estimates based on the normal and Weibull distribution were computed for all tested groups. The descriptive statistics such as the mean, standard deviation (SD) and the corresponding 95\% confidence intervals (95\% CI) 
for each tested FDP group were computed under normal distribution. The interaction between the abutment model and FDP material was investigated using twoway ANOVA and was found to be highly significant $(p<0.001)$. Therefore, the impact of the abutment model was analyzed with two unpaired sample $t$-tests. On the other hand, the one-way ANOVA together with the Scheffé post-hoc test was applied in order to investigate the differences on the fracture load between the FDP material groups. The parameters of the Weibull distribution (shape, scale) and the corresponding 95\% CI were estimated by Maximum Likelihood. Bartlett's modified likelihood ratio tests for the equality of the shape and scale of fracture load were conducted together with the approximate post-hoc test. SPSS Version 20.0 (SPSS INC, Chicago, IL, USA) was used for the normal distribution. The Weibull distribution was performed using MINITAB Version 14.0 (MINITAB, State College, $\mathrm{PA}, \mathrm{USA})^{19)}$. The results of the statistical analysis with $p$-values smaller than 0.05 were considered to be statistically significant.

\section{RESULTS}

The adjusted Anderson-Darling goodness-of-fit estimates in each tested group disclosed that there was no clear preference for the assumed normal or Weibull distribution (Table 2). Therefore both distribution types were used for the analysis of the fracture load data.

\section{Normal distribution}

Descriptive statistics (mean, SD, 95\% CI) of the measured fracture load of each tested group are presented in Table 3. Boxplots of the FDP fracture load for the different FDP materials cemented on base metal alloy or polymeric abutment model are presented in Fig.

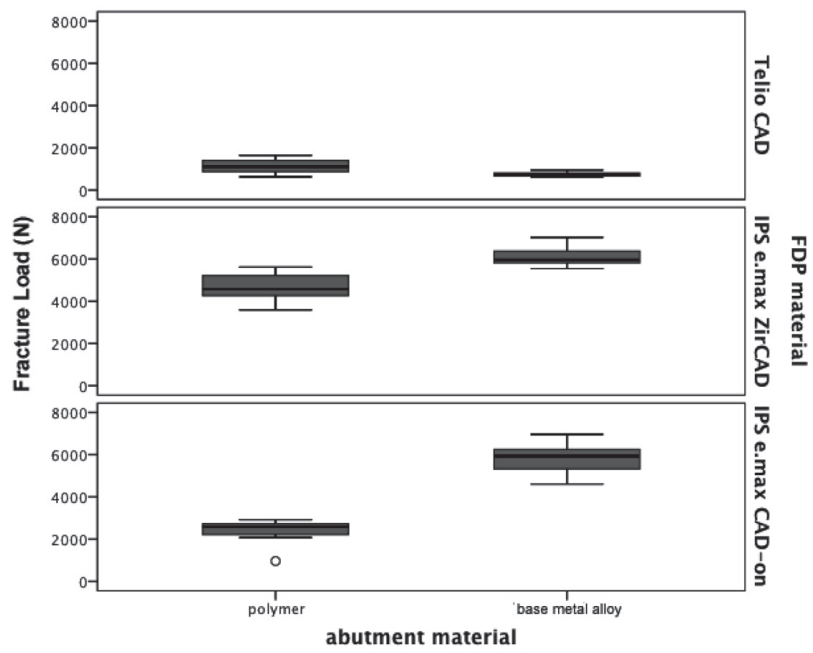

Fig. 2 Boxplot results of all tested groups [N].

Table 2 Adjusted Anderson-Darling (AD) goodness-of-fit estimates for fracture load with failure type total fracture and with failure type chipping under normal and Weibull sampling assumptions. Note that smaller value of $\mathrm{AD}$ means better fit

\begin{tabular}{ccccc}
\hline & FDP material & Model material & Normal & Weibull \\
\hline \multirow{4}{*}{ Total fracture } & Telio CAD & Polymer & 1.144 & 1.188 \\
& Telio CAD & Base metal alloy & 1.177 & 1.604 \\
& e.max ZirCAD & Polymer & 1.151 & 1.241 \\
& e.max ZirCAD & Base metal alloy & 1.421 & 2.322 \\
e.max CAD-on & Polymer & 1.881 & 1.889 \\
Chipping & e.max CAD-on & Base metal alloy & 1.197 & 1.210 \\
& e.max CAD-on & Polymer & 2.085 & 1.884 \\
& e.max CAD-on & Base metal alloy & 1.255 & 1.563 \\
\hline
\end{tabular}

Table 3 Descriptive statistics of fracture load of different FDP and model materials [N]

\begin{tabular}{lccccc}
\hline & \multicolumn{2}{c}{ Polymer } & & \multicolumn{3}{c}{ Base metal alloy } \\
\cline { 2 - 3 } \cline { 5 - 6 } & Mean (SD) & $95 \%$ CI & & Mean (SD) & $95 \%$ CI \\
\hline Telio CAD & $1134(318)^{\mathrm{b}}$ & $(932,1337)$ & & $742(100)^{\mathrm{a}}$ & $(677,806)$ \\
e.max ZirCAD & $4680(616)^{\mathrm{a}}$ & $(4288,5072)$ & & $6111(476)^{\mathrm{b}}$ & $(5808,6414)$ \\
e.max CAD-on (total fracture) & $2398(548)^{\mathrm{a}}$ & $(2029,2766)$ & & $5818(696)^{\mathrm{b}}$ & $(5376,6261)$ \\
e.max CAD-on (chipping) & $833(127)^{\mathrm{a}}$ & $(747,919)$ & & $2275(283)^{\mathrm{b}}$ & $(2084,2465)$ \\
\hline
\end{tabular}

Different superscript letters $(a, b)$ represent a significant difference according to post hoc test between the model materials. 
2. In summary, for all tested groups, the selection of abutment model material was shown to have an impact on the fracture load results $(p<0.001)$. The mean range of fracture load for e.max CAD-on and e.max ZirCAD FDPs cemented on base metal alloy abutments was generally higher than on polymeric abutment groups. In contrast, the Telio CAD groups cemented on the polymeric abutment model presented higher fracture load results compared to groups on base metal alloy support.

Among the groups cemented on base metal alloy abutments, Telio CAD showed the significantly lowest fracture load $(p<0.001)$. Within the polymeric abutment groups, the highest fracture load was observed for e.max ZirCAD, e.max CAD-on and Telio CAD, respectively $(p<0.001)$.

\section{Weibull distribution}

Among e.max CAD-on and e.max ZirCAD groups, the test for equal shape parameters $(p=0.447-0.224)$ indicated that there was no statistical evidence that the Weibull shape parameters (Weibull modulus) differ between FDPs cemented on the base metal alloy or polymeric abutment model (Table 4). Within Telio CAD groups, higher Weibull shape was observed for FDPs cemented on the base metal abutments compared to FDPs cemented on the polymeric abutment model $(p=0.045)$.

The test for equal scale parameters $(p<0.001)$ together with the Bonferroni post-hoc confidence interval indicated that e.max CAD-on and e.max ZirCAD FDPs cemented on the base metal alloy abutments have higher scale parameters (characteristic fracture load) than when cemented on the polymeric abutment models (Table 4). Telio CAD FDPs cemented on the polymeric abutments showed higher scale parameter compared to those cemented on the alloy abutments.

\section{Failure types analysis}

Monolithic zirconia (e.max ZirCAD) and polymeric

Table 4 Weibull statistics (scale, shape) of fracture load with failure type total fracture and with failure type chipping for e.max CAD-on for different model materials [N]

\begin{tabular}{|c|c|c|c|c|c|}
\hline & & \multicolumn{2}{|c|}{ Polymer } & \multicolumn{2}{|c|}{ Base metal alloy } \\
\hline & & Shape & Scale & Shape & Scale \\
\hline Total Fracture & $\begin{array}{c}\text { Telio CAD } \\
\text { e.max ZirCAD } \\
\text { e.max CAD-on }\end{array}$ & $\begin{array}{l}4.2(2.5 ; 6.6)^{\mathrm{a}} \\
9.0(5.6 ; 14.0)^{\mathrm{a}} \\
6.7(3.8 ; 11.4)^{\mathrm{a}}\end{array}$ & $\begin{array}{l}1251(1083 ; 1444)^{\mathrm{b}} \\
4941(4621 ; 5282)^{\mathrm{a}} \\
2577(2353 ; 2821)^{\mathrm{a}}\end{array}$ & $\begin{array}{r}7.8(5.0 ; 11.8)^{\mathrm{b}} \\
13.1(8.5 ; 19.8)^{\mathrm{a}} \\
10.1(6.3 ; 15.7)^{\mathrm{a}}\end{array}$ & $\begin{array}{c}785(725 ; 849)^{\mathrm{a}} \\
6334(6047 ; 6633)^{\mathrm{b}} \\
6112(5759 ; 6486)^{\mathrm{b}}\end{array}$ \\
\hline Chipping & e.max CAD-on & $11.3(6.5 ; 20.0)^{\mathrm{a}}$ & $876(829 ; 925)^{\mathrm{a}}$ & $8.7(5.5 ; 13.5)^{\mathrm{a}}$ & $2398(2229 ; 2578)^{\mathrm{b}}$ \\
\hline
\end{tabular}

Different superscript letters (a, b) represent a significant difference according to post hoc test between the model materials.

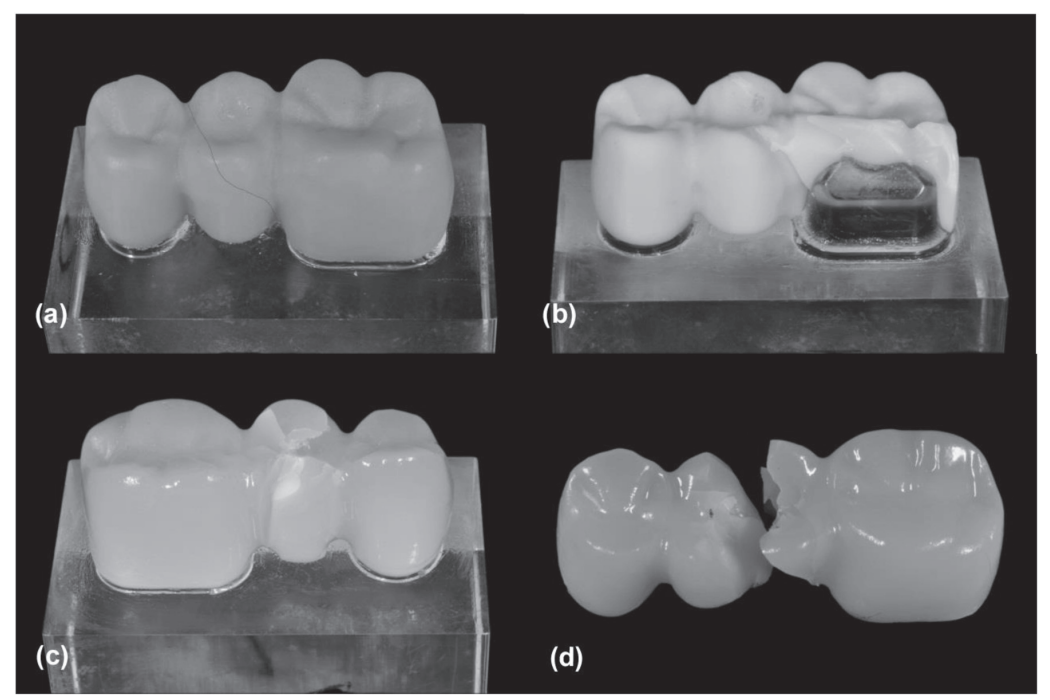

Fig. 3 Typical failure types of different framework materials after fracture load measurement: (a) Telio CAD (total fracture), (b) e.max ZirCAD (total fracture), (c) e.max CAD-on (chipping), (d) e.max CAD-on (total fracture). 
(Telio CAD) FDPs typically fractured between the abutment and the pontic at the connector area. E.max CAD-on showed two fracture types. Chipping in the veneering ceramic was observed first (833-2275 N), and then the zirconia framework fractured (2398-5818 N). The fracture load for failure type chipping showed lower values than for total fracture regardless of the abutment model material (Tables 3, 4 and Fig. 3). Differences in Weibull shape for the different failure types were not observed $(p=0.224)$.

\section{DISCUSSION}

The focus of the present study was to compare different test methods. In this study the abutment model material showed an impact on fracture load results regardless of the FDP material. Indeed, the zirconia FDPs, e.max ZirCAD and e.max CAD-on, cemented on base metal alloy abutments exhibited higher fracture loads than on polymeric abutment groups. However, polymeric FDPs performed conversely. When cemented on the polymeric abutment model higher fracture load results were recorded compared to the FDPs cemented on the base metal alloy model. Thus, the null hypothesis which stated that a higher elastic modulus of the supporting structure leads to increased fracture loads irrespective of the FDP material, is rejected.

Similar findings for all-ceramic FDPs were reported in literature ${ }^{15)}$. The authors registered higher fracture load results for Empress 2 FDPs cemented on alloy abutments than for FDPs cemented on polymeric or extracted human teeth abutments. Other studies on the influence of abutment material investigated allceramic and alloy crowns, however, with inconsistent results: Scherrer et al. ${ }^{14)}$ suggested that the fracture load decreased when monolithic leucite reinforced glass-ceramic restorations (elastic modulus $(E)$ of 69 $\mathrm{GPa}$ ) were supported by abutments with lower elastic moduli. Yet, it should be noted that the authors tested only abutment materials with a small range of elastic moduli (3 $\mathrm{GPa}$ to $14 \mathrm{GPa}$ ); no alloy abutments were employed. The results of Rosentritt et $a l .{ }^{2}{ }^{2}$ showed that Empress 2 crowns $\left(E=104 \mathrm{GPa}^{20)}\right)$ cemented on alloy tooth substitutes $(E=190 \mathrm{GPa})$ and natural incisors $(E=18-20 \mathrm{GPa})$ showed higher fracture load than when cemented on composite abutments $(E=6.8 \mathrm{GPa})^{2)}$. The authors also tested alloy crowns $(E=190 \mathrm{GPa})$. Again the alloy abutments exhibited the significantly highest fracture load, but no statistically significant difference could be detected between the natural incisors and the composite tooth substitutes. The reason for this might be the elastic modulus of the alloy crown, which is twice as high as the elastic modulus of the Empress 2 crown and considerably higher than both the elastic moduli of the natural teeth and composite tooth substitutes. In another study, cementation of Empress 2 crowns was performed on polymeric ( $E=19 \mathrm{GPa})$, human $(E=18-$ $20 \mathrm{GPa})$ and alloy teeth $(E=190 \mathrm{GPa})^{16)}$. The fracture load was significantly higher when the crowns were cemented and loaded on alloy and polymer abutments than on natural teeth. It should be noted that no significant difference could be determined between the fracture loads of crowns cemented on polymeric abutments and crowns cemented on alloy abutments in spite of the high difference in elastic modulus of these two materials. The difference between polymeric abutments and natural teeth, even though both materials have similar elastic moduli, might be explained by the variance in tooth shape, size and preparation design of the extracted teeth. This outcome concerning the comparable behavior of the crowns on alloy and polymeric abutments is contrary to all other findings and, thus far, no explanation has been found.

The reason for the contradictory performance of the Telio CAD FDPs in the present study might be the plastic deformation and the lower flexural strength of this PMMA-based material. The elastic modulus of base metal alloy is more than 50 times higher $(E=200$ $\mathrm{GPa})$ than the elastic modulus of Telio CAD ( $E=3.2$ GPa according to the manufacturer's instructions). In contrast, the difference between the elastic modulus of the polymeric abutment model $(E=3.3 \mathrm{GPa}$ according to the manufacturer's instructions) and Telio CAD is negligible. On the polymeric abutments, the fracture load for Telio CAD was higher $(1134 \mathrm{~N})$ than on the alloy abutments $(742 \mathrm{~N})$ possibly due to the similar deformation of both polymeric PMMA-based materials. In another study, Telio CAD FDPs showed a fracture load of $420 \mathrm{MPa}$ when tested on alloy abutments ${ }^{21}$. This lower value is caused by the size of the connector cross-sectional area, which amounted to $7.36 \mathrm{~mm}^{2}$ in comparison to $31.3 \mathrm{~mm}^{2}$ in the present study. Also, the simulation of the periodontal ligament has probably led to lower values. Moreover, neither the abutments nor the FDPs were anatomically shaped and the FDPs were placed on the abutments without using cement. A further study investigated the fracture load of PMMAbased FDPs with similar composition (Cercon Base PMMA) and reported a mean fracture load of 417 $\mathrm{MPa}^{22)}$. Yet again, the connector cross-sectional area was much smaller $\left(10.2 \mathrm{~mm}^{2}\right)$ and the natural tooth mobility was simulated as the CrCo-alloy abutments were fixed inside a socket with a vinyl-polysiloxane as simulation of periodontal ligament.

When looking at the values achieved with monolithic zirconia, only one study was found in literature. The experimental test set-up differed again strongly from ours, thereby limiting the comparability. The fracture load measured for the three-unit zirconia FDP with a connector size of $29 \mathrm{~mm}^{2}$ cemented on human teeth with simulated periodontal mobility and after aging was $1569 \mathrm{MPa}^{3)}$. In our study the fracture load value of the monolithic zirconia FDPs cemented on the polymeric model was $4680 \mathrm{MPa}$.

Concerning the fracture load of veneered zirconia FDPs, several studies were carried out presenting fracture load values of a wide range. One study observed fracture load results of conventionally veneered zirconia cemented on human tooth abutments ranging between $1011 \mathrm{~N}$ and $2126 \mathrm{~N}^{3)}$. In the present study, the fracture 
load value for e.max CAD-on FDPs on the polymeric abutment model was $2398 \mathrm{~N}$. A fracture load of $2000 \mathrm{~N}$ was recorded when three-unit conventionally veneered DC-Zirkon FPDs (occlusogingival connector height=4 $\mathrm{mm}$ ) were cemented on alloy abutments ${ }^{9}$. In the present study the fracture load amounted to $6111 \mathrm{MPa}$ on the alloy model. In all these studies, the type of veneering differed from our investigation. In the current study, veneering was performed with a $\mathrm{CAD} / \mathrm{CAM}$ generated lithium-disilicate ceramic with a flexural strength of 360 $\mathrm{MPa}^{23}$. Conventional veneering ceramics show flexural strengths of approx. $100 \mathrm{MPa}^{24}$. Furthermore, for the $\mathrm{CAD} / \mathrm{CAM}$ process high quality material is employed with a minimum of flaws compared to conventional veneering. Also, e.max CAD-on crowns showed higher fracture load compared to conventionally fabricated ones $^{23)}$.

The monolithic FDPs, Telio CAD and e.max ZirCAD, typically fractured between the abutment and the pontic at the connector area. This fracture pattern is similar to that reported by other studies ${ }^{9,21,25-26)}$. The veneered zirconia FDP, e.max CAD-on, showed two fracture types ${ }^{13,27}$. First, chipping in the veneering ceramic was observed. When cemented on base metal alloy abutments, the chipping fracture load was significantly lower $(833 \mathrm{~N})$ than when tested on polymeric abutments $(2275 \mathrm{~N})$. Thereafter, the zirconia framework fractured with recorded fracture loads of $2398 \mathrm{~N}$ and $5818 \mathrm{~N}$, respectively. The fracture load for failure type chipping showed lower values than for total fracture regardless of the abutment model material (Tables 3, 4 and Fig. 3).

In summary, all studies showed a variety of experimental set-ups with reference to fatigue loading, connector dimensions, abutment mobility, preparation design, dimensions of core and veneering materials, luting agent, direction, location and type of the applied load and, in particular abutment material. Further studies should be carried out to investigate whether the present results can be transferred to other types of restorations or dental materials. Other tooth-substitute materials should be considered and clinical parameters such as tooth mobility should be simulated. Additionally, long-term effects such as hydrolysis and cycling loading, which can cause deterioration in luting and restoration materials, should be carried out.

\section{CONCLUSIONS}

Within the limitations of this in-vitro study, it can be concluded that:

1. The abutment material has an influence on the fracture load.

2. Zirconia FDPs cemented on base metal alloy abutments showed higher fracture load results than when cemented on polymeric abutments.

3. Polymeric materials cemented on polymeric abutment models presented higher fracture load results compared to groups on base metal alloy support.

\section{ACKNOWLEDGMENTS}

The authors would like to thank Ivoclar Vivadent, Schaan, Liechtenstein for providing the materials.

\section{REFERENCES}

1) Augereau D, Renault P, Pierrisnard L, Barquins M. Threedimensional finite element analysis of the retention of fixed partial dentures. Clin Oral Investig 1997; 1: 141-146.

2) Rosentritt M, Naumann M, Hahnel S, Handel G, Reill M. Evaluation of tooth analogs and type of restoration on the fracture resistance of post and core restored incisors. J Biomed Mater Res B Appl Biomater 2009; 91: 272-276.

3) Rosentritt M, Kolbeck C, Handel G, Schneider-Feyrer $\mathrm{S}$, Behr M. Influence of the fabrication process on the in vitro performance of fixed dental prostheses with zirconia substructures. Clin Oral Investig 2011; 15: 1007-1012.

4) Mahmood DJ, Linderoth EH, Vult Von Steyern P. The influence of support properties and complexity on fracture strength and fracture mode of all-ceramic fixed dental prostheses. Acta Odontol Scand 2011; 69: 229-237.

5) Vult von Steyern P, Kokubo Y, Nilner K. Use of abutmentteeth vs. dental implants to support all-ceramic fixed partial dentures: an in-vitro study on fracture strength. Swed Dent J 2005; 29: 53-60.

6) Kelly JR, Tesk JA, Sorensen JA. Failure of all-ceramic fixed partial dentures in vitro and in vivo: analysis and modeling. J Dent Res 1995; 74: 1253-1258.

7) Kilicarslan MA, Kedici PS, Kucukesmen HC, Uludag BC. In vitro fracture resistance of posterior metal-ceramic and allceramic inlay-retained resin- bonded fixed partial dentures. $J$ Prosthet Dent 2004; 92: 365-370.

8) Luthy H, Filser F, Loeffel O, Schumacher M, Gauckler LJ, Hammerle CH. Strength and reliability of four-unit allceramic posterior bridges. Dent Mater 2005; 21: 930-937.

9) Tinschert J, Natt G, Mautsch W, Augthun M, Spiekermann H. Fracture resistance of lithium disilicate-, alumina-, and zirconia-based three-unit fixed partial dentures: a laboratory study. Int J Prosthodont 2001; 14: 231-238.

10) Kohorst P, Herzog TJ, Borchers L, Stiesch-Scholz M. Loadbearing capacity of all-ceramic posterior four-unit fixed partial dentures with different zirconia frameworks. Eur J Oral Sci 2007; 115: 161-166.

11) Oh WS, Anusavice KJ. Effect of connector design on the fracture resistance of all-ceramic fixed partial dentures. J Prosthet Dent 2002; 87: 536-542.

12) Aboushelib MN, Feilzer AJ, Kleverlaan CJ. Bridging the gap between clinical failure and laboratory fracture strength tests using a fractographic approach. Dent Mater 2009; 25: 383-391.

13) Larsson C, Holm L, Lovgren N, Kokubo Y, Vult von Steyern P. Fracture strength of four-unit Y-TZP FPD cores designed with varying connector diameter. An in-vitro study. J Oral Rehabil 2007; 34: 702-709.

14) Scherrer SS, de Rijk WG. The fracture resistance of allceramic crowns on supporting structures with different elastic moduli. Int J Prosthodont 1993; 6: 462-467.

15) Rosentritt M, Behr M, Gebhard R, Handel G. Influence of stress simulation parameters on the fracture strength of allceramic fixed-partial dentures. Dent Mater 2006; 22: 176182.

16) Rosentritt M, Plein T, Kolbeck C, Behr M, Handel G. In vitro fracture force and marginal adaptation of ceramic crowns fixed on natural and artificial teeth. Int J Prosthodont 2000; 13: 387-391.

17) Ash MM. Wheeler's atlas of tooth form. 5 ed. Philadelphia: Elsevier Health Sciences; 1984. p. 68. 
18) Erdelt KJ, Lamper T. Development of a device to simulate tooth mobility. Biomed Tech (Berl) 2010; 55: 273-278.

19) Roos M, Stawarczyk B. Evaluation of bond strength of resin cements using different general-purpose statistical software packages for two-parameter Weibull statistics. Dent Mater 2012; 28: e76-88.

20) Huang CW, Hsueh CH. Piston-on-three-ball versus pistonon-ring in evaluating the biaxial strength of dental ceramics. Dent Mater 2011; 27 :e117-123.

21) Stawarczyk B, Ender A, Trottmann A, Ozcan M, Fischer J, Hammerle $\mathrm{CH}$. Load-bearing capacity of CAD/CAM milled polymeric three-unit fixed dental prostheses: Effect of aging regimens. Clin Oral Investig 2012; 16: 1669-1677.

22) Alt V, Hannig M, Wostmann B, Balkenhol M. Fracture strength of temporary fixed partial dentures: CAD/CAM versus directly fabricated restorations. Dent Mater 2011; 27: 339-347.

23) Beuer F, Schweiger J, Eichberger M, Kappert HF, Gernet W,
Edelhoff D. High-strength CAD/CAM-fabricated veneering material sintered to zirconia copings - a new fabrication mode for all-ceramic restorations. Dent Mater 2009; 25: 121-128.

24) Stawarczyk B, Ozcan M, Roos M, Trottmann A, Hammerle $\mathrm{CH}$. Fracture load and failure analysis of zirconia single crowns veneered with pressed and layered ceramics after chewing simulation. Dent Mater J 2011; 30: 554-562.

25) Sundh A, Molin M, Sjogren G. Fracture resistance of yttrium oxide partially-stabilized zirconia all-ceramic bridges after veneering and mechanical fatigue testing. Dent Mater 2005; 21: 476-482.

26) Sundh A, Sjogren G. Fracture resistance of all-ceramic zirconia bridges with differing phase stabilizers and quality of sintering. Dent Mater 2006; 22: 778-784.

27) Att W, Grigoriadou M, Strub JR. $\mathrm{ZrO} 2$ three-unit fixed partial dentures: comparison of failure load before and after exposure to a mastication simulator. J Oral Rehabil 2007; 34: $282-290$. 